\title{
Tin electrodeposition from sulfate solution containing a benzimidazolone derivative
}

\author{
Said Bakkali *, Abdelillah Benabida and Mohammed Cherkaoui \\ Laboratoire de Matériaux d'Electrochimie et d'Environnement, Faculté des Sciences, Université Ibn Tofaïl, \\ 14000 Kenitra, Maroc
}

\begin{abstract}
Tin electrodeposition in an acidic medium in the presence of $N, N$ '-1,3-bis-[N-3-(6-deoxy-3- $O$-methylD-glucopyranose-6-yl)-2-oxobenzimidazol-1-yl)]-2-tetradecyloxypropane as an additive was investigated in this work. The adequate current density and the appropriate additive concentration were determined by gravimetric measurements. Chronopotentiometric curves showed that the presence of the additive caused an increase in the overpotential of tin reduction. The investigations by cyclic voltammetry technique revealed that, in the presence and in absence of the additive, there were two peaks, one in the cathodic side attributed to the reduction of $\mathrm{Sn}^{2+}$ and the other one in the anodic side assigned to the oxidation of tin previously formed during the cathodic scan. The surface morphology of the tin deposits was studied by scanning electron microscopy (SEM) and XRD.
\end{abstract}

Keywords: Tin, electrodeposition, $\quad N, N^{\prime}$-1,3-bis-[N-3-(6-deoxy-3-O-methyl-D-glucopyranose-6-yl)-2oxobenzimidazol-1-yl)]-2-tetradecyloxypropane, chronopotentiometry, voltammetry, gravimetry.

\section{Introduction}

Tin is one of the metals most often used in electroplating. This is due to its corrosion resistance, non-toxicity, ductility, excellent wetting properties, high electrical conductivity and its electrical reliability ${ }^{1}$.

Thus, in the food industry, tinplate used for packaging, is often obtained by plating tin on iron. In the field of electronics, tin plating improves corrosion resistance and weldability of copper.

Another interesting application of tin is in the field of lithium ion battery (LIB). Indeed, several studies show that $\mathrm{Sn}$-based materials anodes in LIBs improve their electrochemical performance ${ }^{2-4}$.

Tin deposit is generally obtained from acidic tin (II) or alkaline tin (IV) solutions. Alkaline baths present some difficulty since they work at high temperature and must be protected from $\mathrm{Sn}^{2+}$ ions. By contrast, acidic tin baths are easy to control; however, tin from these electrolytes is strongly deposited even at low polarization. The deposit obtained is then porous and dendritic. The addition of organic additives in the tinning bath improves the quality of the deposit. Thus, to slow the deposition rate, various organic compounds have been used such as aromatic carbonyl ${ }^{5-7}$, reaction products of amine - aldehyde ${ }^{8-9}$ or others compounds ${ }^{10}$.

In this study, we were interested in the effect of a new additive; N,N'-1,3-bis-[N-3-(6-deoxy-3-Omethyl-D-glucopyranos-6-yl)-2-oxobenzimidazol-1yl)]-2-tetradecyloxypropane ${ }^{11}$ (Fig. 1) on the electro-deposition of tin from an acidic solution of tin sulfate. The tin electrodeposition was studied by voltammetric and gravimetric techniques. The deposit was characterized by SEM and XRD.

\section{Experimental Section}

A conventional three-electrode cell was used for the electrochemical investigation. The working electrodes were iron and copper disks with an area of $1 \mathrm{~cm}^{2}$. The potential was measured versus a saturated calomel electrode. The counter electrode is a platinum wire.

Prior each experiment, the solution was deoxygenated by bubbling nitrogen gas for 20 minutes. The working electrode was firstly polished on abrasive paper of grain size ranging from 100 to 1200 , then with alumina and cleaned in an ultrasonic bath for 3 minutes. The Potentiostat used was type VoltaLab PGZ 100 interfaced with a microcomputer. 


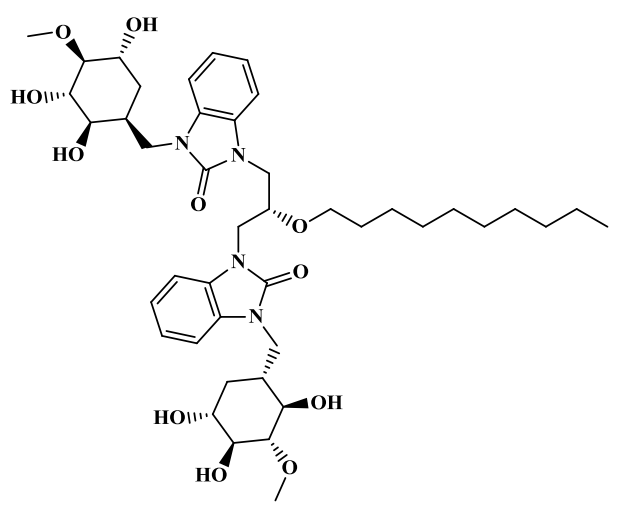

Figure 1. Molecular structure of $N, N^{\prime}-1,3-$ bis-[ $N$-3-(6-deoxy-3-O-methyl-D-glucopyranos-6-yl)-2oxobenzimidazol-1-yl)]-2-tetradecyloxypropane ${ }^{11}$

The SEM observations were made with a scanning electron microscope LEO 1530 FEG kind. XRD measurements were made on a PANalytical diffractometer type X'PERT3 POWDER with $\mathrm{Cu}$ Ka1radiation.

The bath temperature was maintained at $(20 \pm 1){ }^{\circ} \mathrm{C}$. The $\mathrm{pH}$ of the bath solution was measured using a digital $\mathrm{pH}$ meter 510 from Eutech and adjusted with sulphuric acid or sodium bicarbonate solution. All the solutions were prepared from analytical grade chemicals and double-distilled water.

\section{Results and discussion}

\section{Gravimetric measurements}

The Effects of the additive concentration and current density on the deposition rate was determined by gravimetric measurements. For this, deposits were performed on iron rotating electrode (2000 rpm) at variable additive concentrations and different current densities. The electrode was weighed before and after the realization of the deposit. The electrodeposition rate was calculated from the Weight-gain by the formula below ${ }^{12}$.

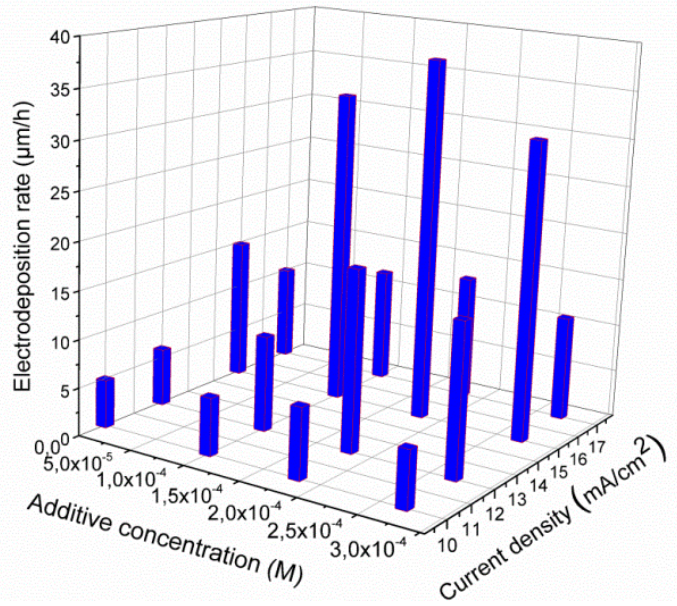

\section{Chronopotentiometric measurements}

In Figure 3 were summarized the chronopotentiometric curves obtained in both electrolytes at $15 \mathrm{~mA} \cdot \mathrm{cm}^{-2}$ on iron rotating electrode. As it can be seen, the presence of the additive in the

$$
v=\frac{m_{f}-m_{i}}{\Delta t . S \cdot \rho_{S n}}
$$

Where $v$ is deposition rate $\left(\mu \mathrm{m} \cdot \mathrm{h}^{-1}\right), \mathrm{m}_{\mathrm{f}}$ is the final mass of the electrode covered with deposit $(\mathrm{g}), \mathrm{m}_{\mathrm{i}}$ is the initial mass of the electrode $(\mathrm{g}), \mathrm{S}$ is the electrode surface $\left(\mathrm{cm}^{2}\right), \Delta \mathrm{t}$ is the time $(\mathrm{h})$ and $\rho_{\mathrm{Sn}}$ is the tin density $\left(\mathrm{g} \cdot \mathrm{cm}^{-3}\right)$.

The results obtained are summarized in Figure 2, which shows that with a concentration of $1.8 \times 10^{-5} \mathrm{M}$ of additive and a current density of $15 \mathrm{~mA} \cdot \mathrm{cm}^{-2}$ the electrodeposition rate reaches its maximum, which is $37.5 \mu \mathrm{m} \cdot \mathrm{h}^{-1}$. In fact, at higher current densities the rate of evolution of hydrogen gas becomes prominent and exceeds metal deposition, which results in lowering of rate of deposition. The presence of additive inhibits the reduction of hydrogen, which improves the deposition rate of tin. As the concentration of the additive becomes important, its blocking effect increases and affects the rate of deposition of tin.

Based on these results the concentration of the additive in the bath solution was fixed at $1.8 \times 10^{-5} \mathrm{M}$.

Figure 2. Electrodeposition rate curves obtained at variable current densities in solutions containing $0.014 \mathrm{M}$ of $\mathrm{SnSO}_{4}, 0.056 \mathrm{M}$ of $\mathrm{H}_{2} \mathrm{SO}_{4}$ and different additive concentrations. The working electrode is Iron rotating disk (2000 rpm). solution increased the overpotential of the metal deposits. This result was obtained with others additives ${ }^{13,16}$. This is caused by the adsorption of the additive on the working electrode surface ${ }^{12-16}$, which impeded the charge transfer ${ }^{17,18}$. 


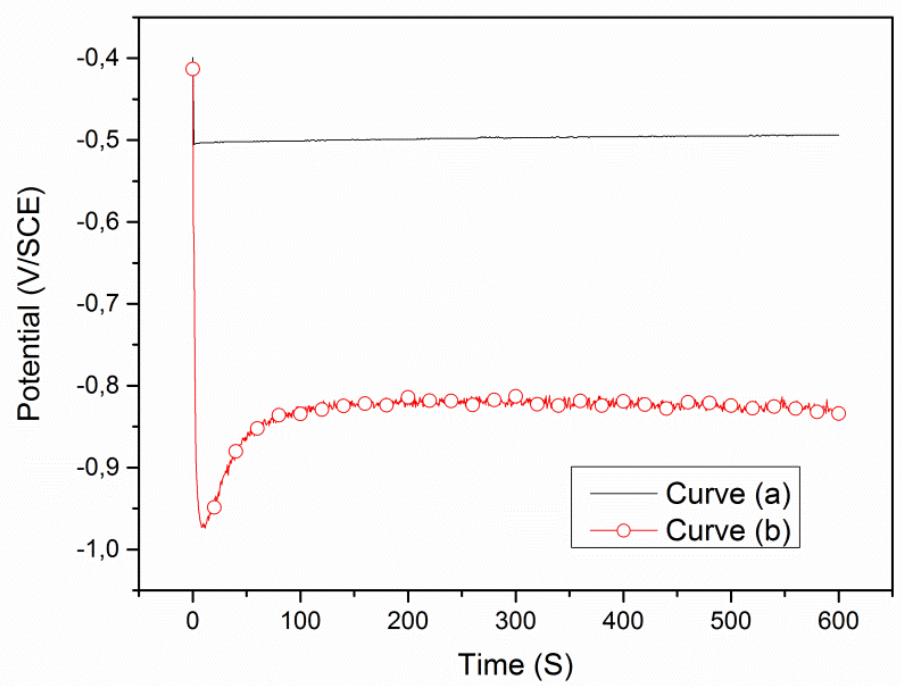

Figure 3. Chronopotentiometric curves recorded using iron rotating electrode (2000 rpm) at $15 \mathrm{~mA} \cdot \mathrm{cm}^{-2}$ obtained during the electroreduction of $\mathrm{Sn}^{2+}$ in solutions: (a) $0.014 \mathrm{M} \mathrm{SnSO}_{4}+0.056 \mathrm{M} \mathrm{H}_{2} \mathrm{SO}_{4}$; (b) $0.014 \mathrm{M} \mathrm{SnSO}_{4}+$ $0.056 \mathrm{M} \mathrm{H}_{2} \mathrm{SO}_{4}+1.8 \times 10^{-5} \mathrm{M}$ additive.

\section{Voltammetric measurement}

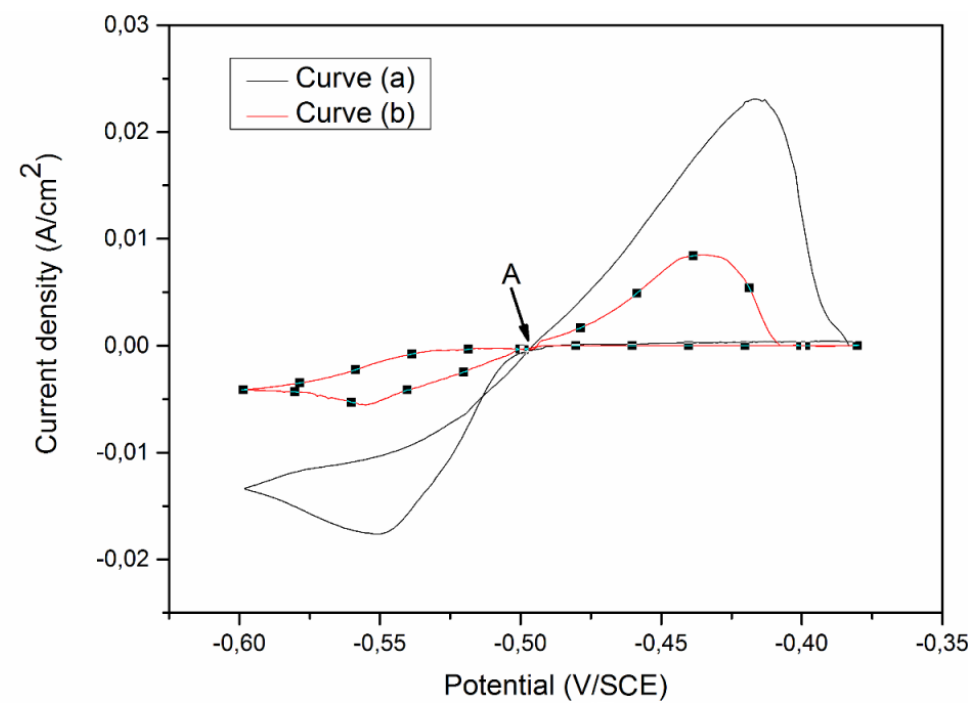

Figure 4. Cyclic voltammetric curves on a fixed copper disc electrode in electrolytes: (a) 0,014 $\mathrm{M} \mathrm{SnSO}_{4}+$ $0,056 \mathrm{M} \mathrm{H}_{2} \mathrm{SO}_{4}$; (b) $0.014 \mathrm{M} \mathrm{SnSO}_{4}+0.056 \mathrm{M}+1.8 \times 10^{-5} \mathrm{M}$ additive. The scan rate was $20 \mathrm{mV} . \mathrm{S}^{-1}$.

To prevent the oxidation of the working electrode during cyclic voltammetry measurements, iron was replaced by copper working electrode. The voltammograms, recorded at a scan rate of $20 \mathrm{mV} \mathrm{s}^{-1}$ in both unstirred electrolytes, are shown in Figure 4. They were initiated at $-0.380 \mathrm{~V}$ vs SCE, scanned in the negative direction and reversed at $-0.6 \mathrm{~V}$ in the positive direction. In both electrolytes, during the forward scan the increase in current observed at the point ' $\mathrm{A}$ ', is assigned to the commencement of the electroreduction of $\mathrm{Sn}^{2+}$ at the cathode. The point 'A' refers to the nucleation potential where tin electrodeposition occurs on the copper electrode. At a more negative potential, a cathodic peak was formed which indicated that the reduction of tin was a diffusion controlled process ${ }^{19}$. When the scan was reversed, the current decreased and a crossover occurred between the cathodic and anodic current traces. The presence of the crossover is diagnostic for the nuclei formation on the electrode ${ }^{19,20}$. At a more positive potential, an anodic peak appeared which corresponds to the dissolution of the deposited Tin previously formed. The current density past the peak was null, indicating the completion of oxidative dissolution of metallic tin at the electrode surface.

The charge density due to cathodic (Q c) and anodic ( $Q$ a) processes can be obtained by integrating the cathodic and anodic branches of the cyclic voltammogram curves, respectively. Table 1 shows the charge density associated with the reduction and oxidation processes in the absence and presence of additives. 
The ratio of the anodic and cathodic charge density $(\mathrm{Qa} / \mathrm{Qc})$ (Table 1$)$ was significantly less than 1 in the additive free bath. This can be explained by the contribution of the reduction of $\mathrm{H}^{+}$to the cathodic current. This ratio increases in the bath with additive. This can be related to the inhibitory effect of the additive on the hydrogen evolution ${ }^{12}$.

Table 1. Cathodic Qc and anodic Qa charges density calculated from the cyclic voltammograms of tin electrodeposition and dissolution.in absence and presence of additive.

\begin{tabular}{|c|c|c|c|}
\hline & $\mathrm{Qc}\left(\mathrm{mC} / \mathrm{cm}^{2}\right)$ & $\mathrm{Qa}\left(\mathrm{mC} / \mathrm{cm}^{2}\right)$ & $\mathrm{Qa} / \mathrm{Qc}$ \\
\hline Solution without additive & 109.45 & 66.79 & $61 \%$ \\
\hline Solution with additive & 22.07 & 20.06 & $91.9 \%$ \\
\hline
\end{tabular}

Effect of the temperature

As shown in Figures 5 and 6 in both solutions the current density at a given potential increases as the temperature increases.

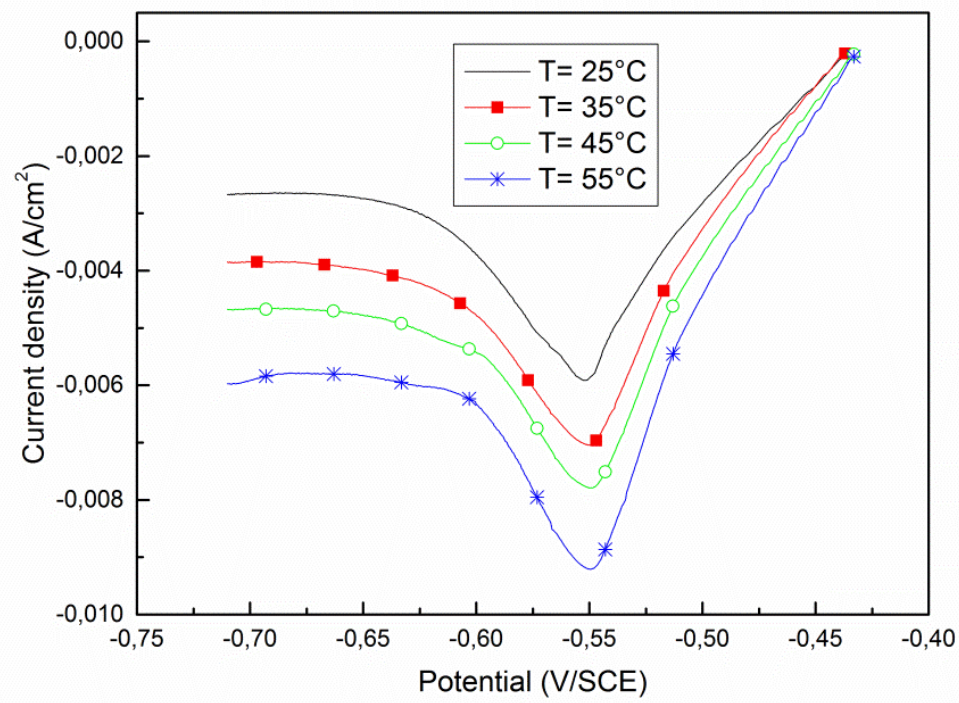

Figure 5. Linear sweep voltammograms in solution containing $0.014 \mathrm{M} \mathrm{SnSO}_{4}+0.056 \mathrm{M} \mathrm{H}_{2} \mathrm{SO}_{4}$ on fixed iron disk at different temperatures. The scan rate was $20 \mathrm{mV} . \mathrm{S}^{-1}$.

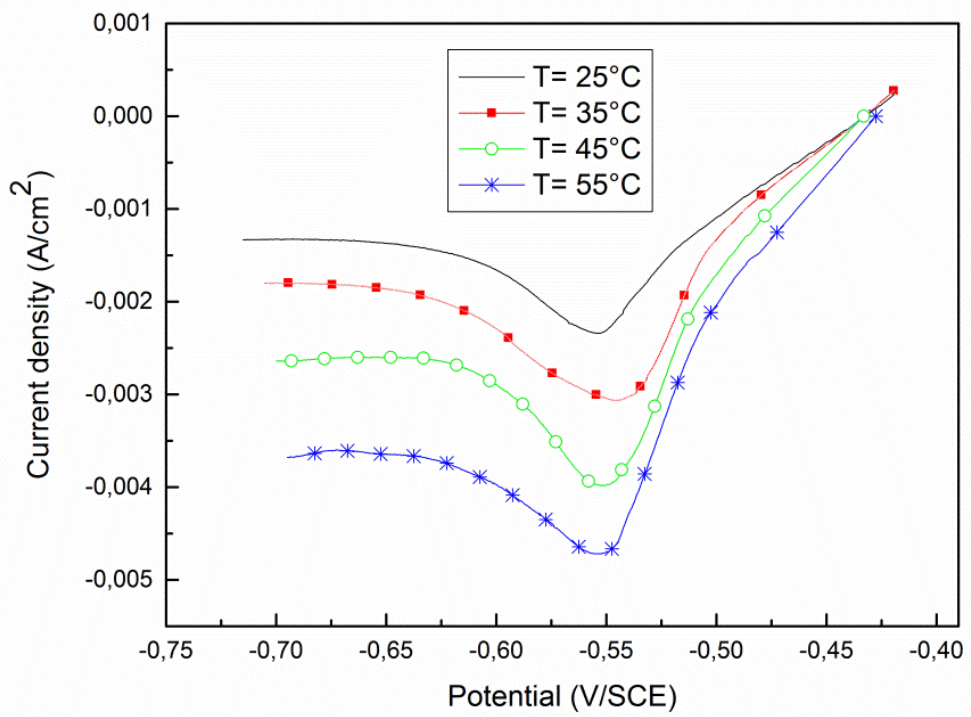

Figure 6. Linear sweep voltammograms in solution containing $0.014 \mathrm{M} \mathrm{SnSO}_{4}+0.056 \mathrm{M} \mathrm{H} 2 \mathrm{SO} 4+1.8 \times 10^{-5} \mathrm{M}$ additive on fixed iron disk at different temperatures. The scan rate was $20 \mathrm{mV} \cdot \mathrm{S}^{-1}$.

The relationship between current density at peak potential and $\mathrm{T}^{-1}$ in each electrolyte is shown in Figure 7. The curves are straight lines; their slopes allowed us to calculate the activation energy of the process using the Arrhenius equation (eq 2). 


$$
\frac{d\left(\log \left(i_{p}\right)\right)}{d\left(\frac{1}{T}\right)}=-\frac{E a}{2.3 * R} \text { (eq 2) }
$$

Where $E_{a}$ is the activation energy of the process and $\mathrm{i}_{\mathrm{p}}$ is the peak current density.

The results obtained are summarized in Table (2).

The activation energy Ea is an important parameter for determining the rate-controlling step. In fact, the diffusion of the electroactive specie is the ratecontrolling step if $E_{a}$ is less than $28 \mathrm{~kJ} \mathrm{~mol}^{-1}$. Values higher than $40 \mathrm{~kJ} \cdot \mathrm{mol}^{-1}$ characterize the adsorption of the species on the reaction surface and subsequent chemical reaction ${ }^{21}$. In all solutions, $E_{a}$ is less than $28 \mathrm{~kJ} \mathrm{~mol}^{-1}$, which indicates a diffusional control of the electrodeposition process in both electrolytes. The results showed also an increase in the activation energy in the solution with the additive. This indicates that the additive increases the energy barrier of the tin reduction. The rise in activation energy value in presence of the additive could be interpreted by physical adsorption occurring in the first stage ${ }^{22,23}$ which explains the nature of organic molecules -metal interactions.

Table 2. activation energy values for each electrolyte.

\begin{tabular}{|c|c|c|}
\hline & Without Additive & With Additive \\
\hline Correlation coefficient $\left(\mathrm{R}^{2}\right)$ & 0.9984 & 0.9928 \\
\hline $\mathrm{E}_{\mathrm{a}}(\mathrm{KJ} / \mathrm{mol})$ & 10.98 & 19.41 \\
\hline
\end{tabular}

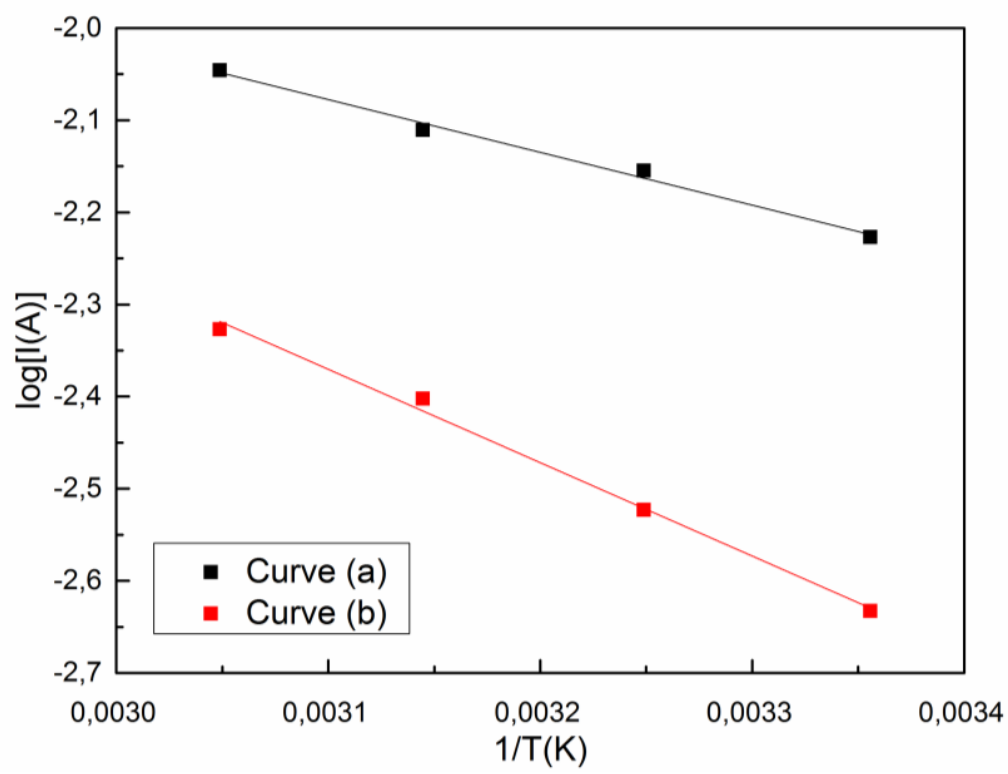

Figure 7. The relation between $\ln \mathrm{i}$ vs. $1 / \mathrm{T}$ on fixed iron disk at peak potential $(-550 \mathrm{mV} / \mathrm{SCE})$ in solutions: (a) $0.014 \mathrm{M} \mathrm{SnSO}_{4}+0.056 \mathrm{M} \mathrm{H}_{2} \mathrm{SO}_{4}$; (b) $0.014 \mathrm{M} \mathrm{SnSO}_{4}+0.056 \mathrm{M} \mathrm{H}_{2} \mathrm{SO}_{4}+1.8 \times 10^{-5} \mathrm{M}$ additive.

\section{Electroplating tin characterisation}

It is well known that the crystal structure of an electrodeposited metal is usually affected by the application of an organic additive ${ }^{24-26}$. To characterise the deposit and to understand the effect of $N, N^{\prime}-1,3$-bis-[ $N$-3-(6-deoxy-3- $O$-methyl-D-glucopyranose-6-yl)-2-oxobenzimidazol-1-yl)]-2-tetra-

decyloxypropane on the crystal structure of the layer electrodeposited, SEM and XRD characterisation were carried out on samples with thickness of about $10 \mu \mathrm{m}$ of deposit performed on iron substrate, from solutions containing or not the additive. The deposit thickness was estimated by the formula:

$$
e=\frac{m_{f}-m_{i}}{S \cdot \rho_{S n}}(\text { eq } 3)
$$

Where $\mathrm{e}$ is the thickness $(\mathrm{cm}), \mathrm{m}_{\mathrm{f}}$ is the final mass of the electrode covered with deposit $(\mathrm{g}), \mathrm{m}_{\mathrm{i}}$ is the initial mass of the electrode $(\mathrm{g}), \mathrm{S}$ is the electrode surface $\left(\mathrm{cm}^{2}\right)$, and $\rho_{\mathrm{Sn}}$ is the tin density $\left(\mathrm{g} . \mathrm{cm}^{-3}\right)$.

\section{Crystallographic structure}

The observed crystallographic distances d(hkl) obtained from the XRD analysis were compared with the expected values given in JCPDS. In both solutions, the peaks in the XRD patterns (Figure 8) can be clearly indexed as the tetragonal Sn (JCPDS card No. 00-004-673) indicating that the deposits Deposits contained only pure phase of Sn.

For evaluating the preferred orientation, which measures the relative degree of preferred orientation among crystal planes of Tin samples, texture 
coefficient Tc was used. It was calculated by the following equation ${ }^{27,28}$.

$$
T C=\frac{\frac{I_{(h k l)}}{I_{0}(h k l)}}{\frac{1}{n} \sum \frac{I_{(h k l)}}{I_{0}(h k l)}}
$$

Where I (hkl) is the relative peak intensity of tin electrodeposits and $\mathrm{n}$ is the number of reflections. The index 0 refers to the relative intensities for the standard tin powder sample (JCPDS card No. 00-
004-673). If the texture coefficient (Tc) is greater than 1.0, it indicates the existence of a preferred orientation.

The Tc values of tin deposits from both solutions are given in table 3 . This Figure shows a strong (200) preferred orientation of the film deposited from additive free solution. Whereas the layer deposited from solution with additive showed a strong (220) preferred orientation. Note that it has been reported that the formation of tin grains oriented along (220) lead to an improved corrosion resistance of the tin film ${ }^{29}$.

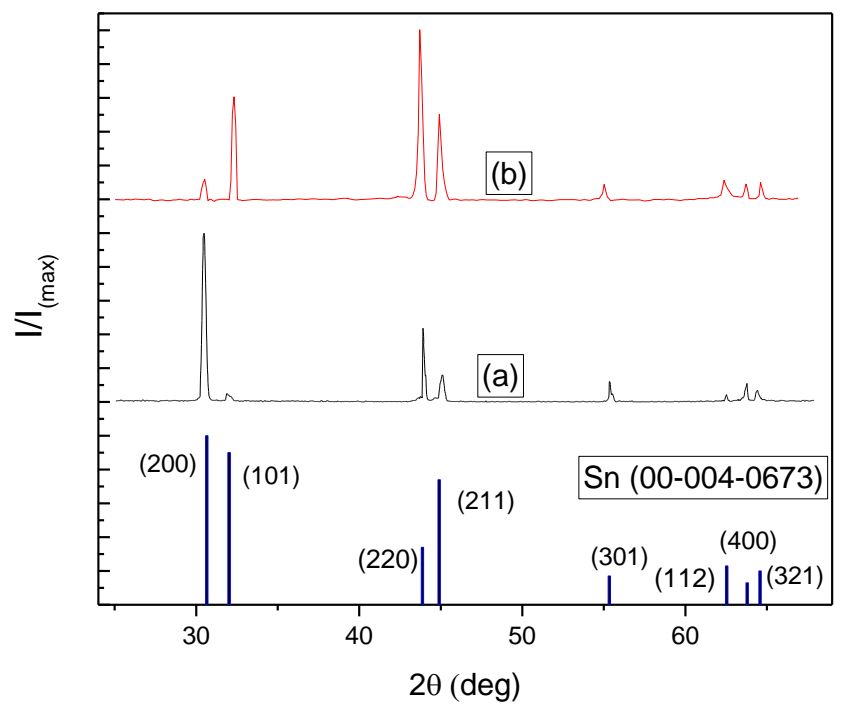

Figure 8: XRD patterns of tin films electrodeposited on iron rotating electrode (2000 rpm) at $15 \mathrm{~mA} / \mathrm{cm}^{2}$ (a) $0,014 \mathrm{M} \mathrm{SnSO}_{4}+0,056 \mathrm{M} \mathrm{H}_{2} \mathrm{SO}_{4}$; (b) $0,014 \mathrm{M} \mathrm{SnSO}_{4}+0,056 \mathrm{M}+1.8 \times 10^{-5} \mathrm{M}$ additive.

Pattern of tin (JCPDS card No. 00-004-673) has been given for reference.

Table 3. Texture coefficients of different planes of tin coatings electrodeposited from both solutions.

\begin{tabular}{|c|c|c|}
\hline .Planes & Solution without additive & Solution with additive \\
\hline$(200)$ & 2,19882 & 0,14873 \\
$(101)$ & 0,12216 & 0,82626 \\
$(220)$ & 1,61678 & 3,64528 \\
$(211)$ & 0,46948 & 0,83743 \\
$(301)$ & 1,36558 & 0,65231 \\
$(112)$ & 0,38407 & 0,54122 \\
$(400)$ & 1,29342 & 0,72906 \\
$(321)$ & 0,5497 & 0,6197 \\
\hline
\end{tabular}

\section{Morphology of the deposits}

The changes in Tin deposit occurring in the presence of the additive were also confirmed with the help of morphological studies (Figure. 8). In fact, in additive free solution, the tin deposit was porous, dendritic and had an irregular form, $\mathrm{Cu}$ substrate can also be seen in some places confirming the poor cathode coverage; the deposit had also different and slightly larger crystal sizes. (Figure. 10a). In contrast, the SEM photomicrograph of the deposit from the bath with additive showed a uniform arrangement of crystals, refinement in the crystal size which was around $3-4 \mu \mathrm{m}$ and a bright deposit. (Figure. 10b). This is due to the adsorption of additive molecules on the electrode surface, which decreased the surface diffusion of anions toward the active growth sites and thus retarded grain growth. 

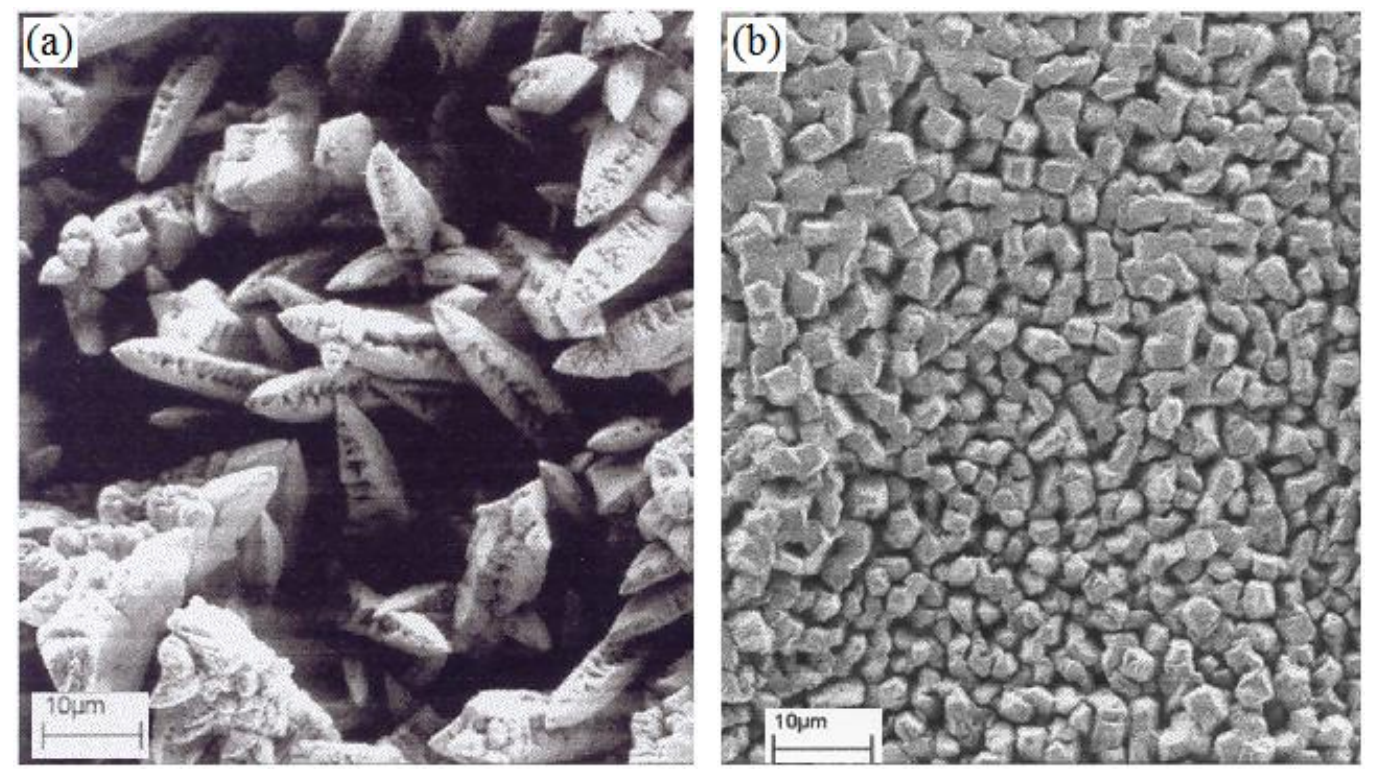

Figure 10. SE Micrographs of the deposits obtained on iron rotating electrode $(2000 \mathrm{rpm})$ at $15 \mathrm{~mA} / \mathrm{cm}^{2}$ (a) $0,014 \mathrm{M} \mathrm{SnSO}_{4}+0,056 \mathrm{M} \mathrm{H}_{2} \mathrm{SO}_{4}$; (b) $0,014 \mathrm{M} \mathrm{SnSO}_{4}+0,056 \mathrm{M}+1.8 \times 10^{-5} \mathrm{M}$ additive.

\section{Conclusion}

Electrodeposition of tin from acidic bath in the absence and presence of $N, N^{\prime}-1,3-$ bis-[N-3-(6-deoxy3-O-methyl-D-glucopyranose-6-yl)-2-oxobenzimidazol-1-yl)]-2-tetradecyloxypropane as additive was investigated, in order to study the influence of this additive on the mechanism and kinetics of $\mathrm{Sn}$ (II) ions reduction, as well as the morphology of the resulting Sn coatings. A concentration of $1,8.10^{-5} \mathrm{M}$ of the additive and current density of $15 \mathrm{~mA} / \mathrm{cm}^{2}$ were optimum to improve the deposition speed. The additive has increased the overpotential of tin reduction and affected the hydrogen evolution was but has not modified the shape of the voltammogram In fact, two peaks were observed, one in the cathodic range and another in the anodic one. The reduction of $\mathrm{Sn}^{2+}$ ions was controlled by diffusion in both solutions.

The study of X-ray diffraction patterns showed that the films deposited from both solution were formed from pure tin and that the presence of additive affected the preferred growth orientation of tin film and improves the quality of deposited film which became regular and smooth. All these results could be explained by the adsorption of the additive on the working electrode surface.

\section{References}

1- J. M. Bureka, A. S. Budiman, Z. Jahed, N. Tamura, M. Kunz, S. Jin, S. Min J. Han, G. Lee, C. Zamecnik, T. Y. Tsui, Materials Science and Engineering, 2011, A528, 5822-5832.

2- F. Wanga, L. Chen, C. Deng, H. Ye, X. Jiang, Ga. Yang Electrochimica Acta 2014, 149, 330-336
3- K. Zhuo, Myung-Gi Jeong, C-Hwa Chung Journal of Power Sources, 2013, 244, 601-605.

4- D. T. Mackay, M. T. Janish, U. Sahaym, P. G. Kotula, K. L. Jungjohann, C. B. Carter, M. G. Norton Journal of Materials Science, 2014, 49, 1476-1483.

5- N. Kaneko, N.Shinohara, H. Nezu, Electrochem. Acta, 1992, 37, 2403-2409.

6- Y. Nakamura, N.Kaneko, H.Nezu, Journal of Applied Electrochemistry, 1994, 24, 569-574.

7- N. Dohi, Journal of the Metal Finishing Society of Japan, 1970, 21, 240.

8- M. Clarke, S. C. Britton, Transactions of the Institute of Metal Finishing, 1962, 39, 5.

9- M. Clarke, J. A. Bernie, Electrochimca. Acta, 1967, 12, 205.

10- S. Bakkali, T. Jazouli M. Cherkaoui, M. Ebntouhami, N. El Hajjaji., E. Chassaing Plating and Surface finishing, 2003, 90, 46- 49.

11- B.Lakhrissi, L.Lakhrissi, M.Massoui, E.M.Essassi, F.Comelles, J.Esquena, C.Solans, C.Rodrýiguez-Abreu, Journal of Surfactants and Detergents, 2010, 13, 329-338.

12- S. Bakkali, R. Touir, M. Cherkaoui, M. Ebn Touhami Surface \& Coatings Technology 2015, 261, 337-343.

13-M. Charrouf, S.Bakkali, M.Cherkaoui, M. EL Amrani, Journal of the Serbian Chemical Society. 2006, 71(6), 661-668.

14- S. Bakkali, M. Charrouf, M. Cherkaoui, Physical and Chemical News, 2005, 25, 110-117.

15- S.Bakkali, M. Cherkaoui, M. Belfaquir, ScienceLib Editions Mersenne, juillet 2013, 5, 130705, 1-13.

16 -S. Tzeng, S. H Lin, Y.Y.Wang, C.C.W an, Journal of a pplied electrochemistry 1996,26,419-423. 
17- J. O'M Bockris and K. N. Reddy, 'Modern Electrochemistry', Vol. 2, Plenum, New York, 1975, 969.

18- J Long, Z. Zhang, ZC Guo, X.Y. Zhu, H. Huang Advanced Materials Research, 2012, 460, 7-10.

19- I. Petersson, E. Ahlberg Journal of Electroanalytical Chemistry, 2000, 485, 166-177.

20- A.M. I. Magdy, M. A. O. Enam, Surface \& Coatings Technology, 2013, 226, 7-16.

21- H. M.A. Soliman Applied Surface Science, 2002, 195, 155-165.

22- N.P. Clark, E. Jakson, M. Robinson, British Corrosion Journal. 1979,14, 33.

23- Lj. M. Vracar, D.M. Drazic Corrosion Science, 2002, 44, 1669-1680.
24- J.Y. Lee, JW Kim, MK Lee J Electrochem Soc, 2004, 151, 25-25.

25- G Trejo, H Ruiz, R OrtegeBorges et al J Appl Electrochem, 2001, 31, 685.

26- DS Baik, DJ Fray J Appl Electrochem., 2001, 31, 1141.

27- K.S. Kim, C.H. Yu, J.M. Yang, Microelectronics Reliability, 2006, 46, (7), 1080-1086.

28- A. Dilawar, M.Z. Butt, I. Muneer, F. Bashir, M. Saleem, International Journal for Light and Electron Optics, 2017, 128, January, 235-246.

29- P. Eckold, R. Niewa, and W. Hügel, Microelectronics Reliability, 2014, 54, (11), 2578-2585. 